\title{
AbBREViations AND Conventional SIGNS
}

\author{
(...) completed by the editor (abbr.) \\ [...] the missing text cannot be supplied (reconstructed) \\ $\langle\ldots\rangle \quad$ supplied by the editor \\ $=\quad$ corresponds to, is the same as \\ a.c. ante correctionem \\ AAV Archivum Apostolicum Vaticanum \\ abbr. in abbreviatura \\ add. addidit \\ AHU Arquivo Histórico Ultramarino, Lisbon \\ alterum the other, the second (of the two) \\ ANTT Arquivo Nacional da Torre do Tombo, Lisbon \\ ARSI Archivum Romanum Societatis Iesu \\ B.O.C. Biblioteca Orientalis Clementino-Vaticana \\ $B P P \quad$ Bullarium Patronatus Portugalliae Regum in Ecclesiis \\ BPPA Bullarium Patronatus Portugalliae in Ecclesiis Appendix \\ C.M.G. $\quad$ C. M. George (trans.) De Erroribus Nestorianorum (1986) \\ ca. circa \\ cha. chapter (S.D) \\ coni. conicit \\ corr. correctio \\ d. died \\ D.I. Documenta Indica \\ dec. decree (S.D) \\ del. delevit \\ dist. distinxit \\ E.P. $\quad$ Enformação do Prelado do Serra (1594)
}


e.t. $\quad$ error transcriptionis

ed. (eds.) edited by

et passim and throughout

f. ff. folium, folii

fort. fortasse

G ARSI, Goa-Mal. 50, 198r-214v . De Erroribus Nestorianorum qui in hac India Orientali Versantur (1587)

gl. glossa

Goa-Mal. Goa-Malabar (ARSI)

$H \quad$ Hausherr Irénée S.J (ed.) De Erroribus Nestorianorum (1928)

I.L. Inquisição de Lisboa, proc. 4941 (ANTT). Interrogatorios de certas heresias et erros Nestorianos (1596)

L.V. $\quad$ Latin Vulgate

mg. $\quad$ in margine

mut. mutavit

n. note

N.I.C.T. $\quad$ Novum Iesu Christi Testamentum (1616)

N.T New Testament

om. omisit

O.S.A. Ordo Fratrum Sancti Augustini (Augustinians)

O.P. Ordo Fratrum Praedicatorum (Dominicans)

$P \quad$ Peshitta

p.c. post correctionem

prem. premit (emphasized word/words)

prius the earlier, the first (of the two)

pro instead of

$r$ (s.s) recto

r. $\quad$ reigned (ruled)

ras. in rasura

S.D. $\quad$ Synod of Diamper (1599)

S.I (S.J) Societatis Iesu (of the Society of Jesus)

s.l. supra lineam

s.s. suprascriptum

scripsi emended by the editor

Sess. $\quad$ Session (S.D)

sic sic erat scriptum

sq. sequens 
STC Saint Thomas Christians

suppl. supplevit

T Fondo Tacchi Venturi, b. 26 fasc. 27, ff. $10^{\mathrm{r}}-19^{\mathrm{v}}$ (ARSI)

De Syrorum Orientalium Erroribus (1586)

trai. traiecit

trans. translated by, translation

transp. transposuit

trib. tribuit

$\mathrm{v}$ (s.s) verso

$V \quad$ Codice Vaticano Siriaco, 83

v.l. (vv.ll.) varia lectio (variae lectiones)

vid. videtur 
